NASA Technical Memorandum 107285

AIAA-96-2582

\title{
A Performance Comparison of Two Small Rocket Nozzles
}

Lynn A. Arrington

NYMA, Inc.

Brook Park, Ohio

Brian D. Reed

Lewis Research Center

Cleveland, Ohio

Angel Rivera, Jr.

University of Texas

San Antonio, Texas

Prepared for the 32nd Joint Propulsion Conference cosponsored by AIAA, ASME, SAE, and ASEE Lake Buena Vista, Florida, July 1-3, 1996

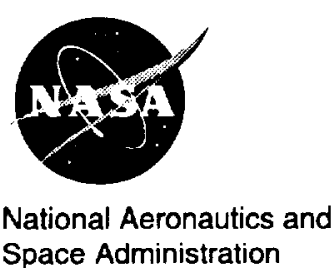





\title{
A Performance Comparison of Two Small Rocket Nozzles
}

\author{
Lynn A. Arrington \\ NYMA, Inc. \\ Brookpark, Ohio 44142 \\ Brian D. Reed \\ National Aeronautics and Space Adminstration \\ Lewis Research Center \\ Cleveland, Ohio 44135 \\ and \\ Angel Rivera, Jr. \\ Undergraduate, Senior \\ University of Texas \\ San Antonio, Texas
}

\begin{abstract}
An experimental study was conducted on two small rockets ( $110 \mathrm{~N}$ thrust class) to directly compare a standard conical nozzle with a bell nozzle optimized for maximum thrust using the Rao method. In large rockets, with throat Reynolds numbers of greater than $1 \times 10^{5}$, bell nozzles outperform conical nozzles. In rockets with throat Reynolds numbers below $1 \times 10^{5}$, however, test results have been ambiguous. An experimental program was conducted to test two small nozzles at two different fuel film cooling percentages and three different chamber pressures. Test results showed that for the throat Reynolds number range from $2 \times 10^{4}$ to $4 \times 10^{4}$, the bell nozzle outperformed the conical nozzle. Thrust coefficients for the bell nozzle were approximately 4 to 12 percent higher than those obtained with the conical nozzle. As expected, testing showed that lowering the fuel film cooling increased performance for both nozzle types.
\end{abstract}

\section{Introduction}

Future space exploration will require increasing payload fraction and decreasing system masses. Therefore, maximizing rocket engine performance is an important design goal. Maximizing the thrust for a rocket engine can be achieved by optimizing the nozzle contour. Optimizing the performance of finite length nozzles is typically accomplished using an inviscid core flow and a boundary layer displacement. G.V.R. Rao developed a method which optimizes a rocket nozzle contour for a given length or expansion ratio such that maximum thrust is achieved. ${ }^{1}$ Rao's method was based on the assumption of inviscid isentropic flow.

This method has been used in many studies of different classes of rocket engines with a variety of results. Rocket engines are generally classified by their throat Reynolds number based on uniform flow and properties at the throat. For engines with Reynolds numbers larger than $1 \times 10^{5}$, the Rao optimization is quite effective, because the ratio of boundary layer flow to the total flow is small. In a study by Farley, ${ }^{2}$ three large Rao optimized bell nozzles were compared to a 15 degree conical nozzle. The thrust produced by the optimized nozzles was greater than that obtained with the conical nozzle. In fact, bell contour nozzles have been used routinely for many years in large liquid rocket engines. $3,4,5$ Conical nozzles are typically used only when fabrication and design costs outweighed performance.

In very small thrusters with Reynolds numbers less than $1 \times 10^{4}$, viscous boundary layer effects are large in comparison to the total flow and a bell contour is not nearly as effective, as discussed in a pair of experimental studies. ${ }^{6,7}$ In these studies, a variety of small nozzles were tested to determine the effect of contour, propellant, expansion ratio, and Reynolds number on performance. Normally, factors in performance loss are divergence, boundary layer effects, and heat transfer effects to the walls. By using ambient temperature gas, the heat transfer effect was eliminated in both studies. The nozzles were conical, trumpet, and Rao optimized bell contours. One paper concluded that the difference in contours had no effect on either divergence or viscous losses. ${ }^{6}$ The other concluded the bell contour had the lowest performance of the nozzles tested. ${ }^{7}$ The reasons given in both were that the viscous effects of boundary layer were so large that an inviscid isentropic assumptions were not valid.

For rockets that are sized between the very small and large ones the usefullnes of the Rao optimization code is less clear. Investigations on a gaseous hydrogen/oxygen engine were 
performed by M.A. Appel with different nozzle contours in the 134 to $445 \mathrm{~N}$ thrust class. ${ }^{8}$ A menium 80 percent bell nozzle, a regeneratively cooled nozzle, and a stainless steel 18 degree half angle conical nozzle were each tested using the same injector in this effort. The stainless steel nozzle was built to verify injector and thrust stand operation prior to testing the other two nozzles. The regeneratively cooled nozzle had different dimensions for a different aspect of the study, but the conical and bell nozzles had the same length, exit area and expansion ratio. Unexpectedly, the test results showed that the conical nozzle provided a higher specific impulse than the bell nozzle. The author postulated that the conical nozzle operated with a higher kinetic efficiency and suggested this as an area for further investigation. Kushida ${ }^{9}$ examined a $22 \mathrm{~N}$ monopropellant hydrazine thruster with a 100:1 area ratio conical nozzle, a 300:1 Rao optimized bell, and the same bell nozzle cut off at expansion ratios of 200:1 and 100:1. Results showed that the $300: 1$ bell nozzle outperformed the conical chamber but the conical was the better performer than the lower area ratio bell nozzles. A direct comparison was difficult, however, because several dimensions were changed in addition to the nozzle contours. Both the length and expansion ratio were greater for the optimized nozzle, which generally improves performance in a rocket engine. Based on the ambiguous results reported to date, the validity of the Rao nozzle optimization method is uncertain for thrusters with Reynolds numbers between $1 \times 10^{4}$ and $1 \times 10^{5}$.

In the study reported herein, testing was performed to directly evaluate the applicability of Rao optimization methods to rockets with Reynolds numbers below $1 \times 10^{5}$. The performance of two $110 \mathrm{~N}$ chamber/nozzles with throat Reynolds numbers between $2 \times 10^{4}$ and $4 \times 10^{4}$ was measured to examine the effect of nozzle contour on performance in this intermediate Reynolds number range. Both nozzles were designed with the same chamber profile, throat diameter, and expansion ratio. Because the chamber and nozzle are one continuous structure, each piece of hardware is simply identified by the nozzle shape, ie. bell or conical, from here on. The conical nozzle had a 19 degree expansion half angle. This rocket was originally tested in 1993. ${ }^{10}$ The bell nozzle was designed via the Rao code. As part of the effort, a one dimensional equilibium code, ODE, was used to generate theoretical performance predictions to calculate the characteristic velocity efficiencies presented later in this study. ${ }^{11}$

\section{Test Hardware}

Both nozzles tested were fabricated via the same techniques using oxygen free high conductivity (OFHC) copper with water cooling passages in the walls. The inner housings were milled first to cut water cooling passages into the outer surface. The chamber profiles were identical from the injector face to the throat. The contours of the nozzles are shown in figures 1 (a) and (b), and further details of the bell nozzle contour are given in table I. The divergence angle of the conical nozzle was about 19 degrees and the divergence angle of the bell nozzle was about 9 degrees at the exit plane. The design specified throat area was $1.267 \mathrm{~cm}^{2}$. Post fabrication measurements of the chamber, throat, and exit gave dimensions that were very similar as shown in table II. The resulting dimensional differences based on area were 0.10 percent at the chamber, 2.2 percent at the throat, and 0.14 percent at the nozzle exit.

The outer housing of each nozzle was machined in two pieces separated along the thruster axis. The sections fit around the inner housing as a shell to insure the interior contour was one continuous profile from chamber inlet to nozzle exit. The outer housing halves were attached to each other with bolts around the inner housing. All seams were filled with high temperature solder. Both chambers were instrumented with thermocouples and pressure taps in several quadrants along the contour.

The same injector, ${ }^{12}$ shown schematically in figure 2, was used in all testing. The injector was designed to produce a core flow of combustion products with an annulus of fuel film cooling (FFC). In the core, oxygen was injected through a platelet stack into the combustion chamber just upstream of a spark plug used for ignition. The hydrogen flow was divided by means of a fuel splitting washer, with part injected downstream of the spark plug into the core and the rest used to fuel film cool the chamber wall. The washer was specifically designed to give a predetermined fuel film cooling split from the total fuel flow. The film cooling was directed along the chamber walls by an annular sleeve. By changing the washer, the amount of film cooling could be varied between 55 to 85 percent. A 61 percent FFC percentage was selected as the baseline for this study since that was nominal design operating point for this injector. Tests at 75 percent FFC were also run to investigate the sensitivity to FFC changes.

\section{Test Facility}

All tests were conducted in a small rocket test facility, ${ }^{13}$ in which an equivalent vacuum of $36.6 \mathrm{~km}$ altitude is achieved using air ejectors. Gaseous hydrogen and gaseous oxygen were used for propellants. A schematic is shown in figure 3. The tank is $1.8 \mathrm{~m}$ long between the flanges and $0.9 \mathrm{~m}$ in diameter. Inside the tank, the rockets are oriented horizontally to fire through a diffuser into an exhaust quenching chamber. The rocket exhaust is pulled through the pair of ejectors and vented to atmosphere by mufflers. The ejectors are supplied with $900 \mathrm{kPa}$ air at $4.5 \mathrm{~kg} / \mathrm{sec}$ to provide the pumping for the altitude tank.

Thrust is measured by mounting the rocket on a thrust stand. The stand and rocket are supported with flexure plates. Both float free on the flexures and apply a load to a strain gage load cell through a ball joint. To ensure accurate thrust calibration, the ball joint must make contact with the load cell at all times. The thruster is positioned to apply a small load on the load cell 
even when the thruster is not firing, to ensure contact with the load cell is maintained. The small load is accounted for in thrust calibration and is subtracted from the rocket thrust. The propellant and pressure transducers lines are mounted perpendicular to the rocket axis with stainless steel tubing to provide repeatable thrust measurements. The thrust stand is calibrated by applying loads through a piston assembly to compare the thrust measurement load cell against another previously calibrated reference load cell. Pretest, posttest, and applied load tests are taken at altitude conditions with pressurized propellant lines. All thrust measurements are corrected for background pressure to determine vacuum thrust.

\section{Rao Optimization Code}

Rao discussed the need for nozzle contour optimization. ${ }^{14}$ In order to maximize thrust, a thruster is designed to produce uniform parallel exit flow, with the exit plane pressure equal to the ambient pressure. In a conical nozzle, flow divergence losses are significant, particularly as cone angles increase. Rao suggested that contouring the nozzle wall would turn the flow closer to the thruster axis and thus reduce flow divergence. He developed an optimization method for designing nozzles which assumes inviscid isentropic flow. ${ }^{15}$ The method uses the calculus of variations for an ideal gas with constant gamma expansion to calculate the optimum nozzle contour. Supersonic flow properties across the nozzle throat are input to start the solution. Transonic flow in the throat region is calculated as a function of the upstream radius of curvature at the throat and the specific heat ratio for axisymmetric flow. The method iterates to an optimum nozzle contour defined to meet for one of three initial conditions: a given length, a given expansion ratio, or a fixed envelope (exit radius and length). The Rao code was used in this study to obtained an optimized bell nozzle contour with the dimensions shown in table I using the fixed envelope condition.

\section{Test Procedures}

The same tests were conducted on each nozzle using gaseous hydrogen and oxygen propellants. Tests were conducted at three different chamber pressures, $500,370,255 \mathrm{kPa}$, and two FFC percentages, 61 and 75 percent, over a mixture ratio range of 4 to 8 . The design condition for the rocket hardware was $500 \mathrm{kPa}$ with 61 percent FFC. The higher FFC percentage and the lower chamber pressures were chosen to allow testing through a throat Reynolds number range of $2 \times 10^{4}$ to $4 \times 10^{4}$. The throat Reynolds number ( $\mathrm{Re}$ ) range was calculated using the equation

$$
\operatorname{Re}=\frac{4 \dot{m}}{\pi \mu D_{t}}
$$

where $m$ is the mass flow rate of the propellants, $\mu$ is the absolute viscosity of the combustion products, and $D_{t}$ is the diameter of the nozzle throat. The viscosity is determined from theoretical predictions generated by the Gordon-McBride program. ${ }^{11}$ The two percent difference in throat areas sometimes resulted in slightly lower chamber pressure in the conical nozzle. A typical test began by pumping the test tank to altitude and pressurizing the propellant lines with fuel. A thrust stand calibration was then performed. After the calibration, a constant load was applied to the thrust stand, which provided data for determining the uncertainties. Once the applied load was removed and inlet pressure conditions at the injector were adjusted, the rocket engine was fired. By modifying the propellant inlet pressures, mixture ratios from 4 to 8 were tested. Once tests were completed for the day, another constant load test and another load cell calibration were conducted.

\section{Measurement Uncertainties}

Measurement uncertainties were calculated using the JANNAF recommended procedure. ${ }^{16}$ The uncertainties were calculated from the precision (random) and bias (constant) errors associated with the measurement instruments and data acquisition system. Precision errors propagated through the performance parameters of specific impulse, characteristic velocity, and thrust coefficient are shown in table III. Initial testing with the bell nozzle for the 500 and $370 \mathrm{kPa}$ chamber pressure cases at 61 percent FFC had a very small pretest load (less than $0.5 \mathrm{~N}$ ) on the thrust stand prior to ignition. Since the thrust stand could float free of the load cell at this load, a larger load was applied prior to ignition to ensure pretest contact between the thruster and the load cell. The low pretest load affected the repeatability of the thrust stand zero. In an effort to ensure that the thrust measurement was not affected by the small pretest load, the pretest load was increased and a few selected points in that test series were repeated. A field check at that time showed performance results consistent with the original tests at the smaller pretest load. However, in subsequent data reductions, the tests with the small pretest load had significantly larger uncertainties. The range of uncertainties for both cases are shown in table III, the cases with the smaller pretest load being indicated by parenthesis. The remainder of the test data uncertainties were also presented in the same table. In general, the greatest uncertainties were at the lower chamber pressures.

\section{Results and Discussion}

\section{Injector/Chamber Performance}

To show that the injector and chamber behaved identically for the two nozzles, the characteristic velocity efficiencies are 
plotted in figures 4 and 5 as a function of mixture ratio for tests run at 61 and 75 percent FFC, respectively. The efficiencies were determined by dividing the experimental characteristic velocity by the theoretical equilibrium characteristic velocity predictions. ${ }^{11}$ As expected, the plots show no measurable differences in this parameter between the bell and conical nozzles as the injector and chamber profiles are the same. The slight difference in throat area resulted in slightly higher chamber pressures (approximately 1 percent), in the bell nozzle for the same inlet conditions. Clearly the difference did not have a measurable impact on the performance of the injector and chamber, since the characteristic velocities measured with both nozzles fell within the same uncertainty band. The overall efficiency is slightly higher for the 61 percent FFC cases. This was an expected result because more hydrogen is reacted in the core combustion flow at this condition. Similiar trends are shown in the plots of characteristic velocity versus mixture ratio (figs. 6 and 7 ).

\section{Nozzle Performance}

Vacuum specific impulse versus mixture ratio and thrust coefficient versus mixture ratio are typically used to illustrate nozzle performance. The vacuum specific impulse versus mixture ratio for the 61 and 75 percent FFC cases are plotted in figures 8 and 9 , respectively, for each of the three chamber pressures tested. The data were fit to a second order polynomial curve and the measurement uncertainties added. At 61 percent FFC (fig. 8), the plots of nozzle data show that the bell nozzle specific impulse are at least 5 percent higher at $500 \mathrm{kPa}$, 6 percent higher at $370 \mathrm{kPa}$, and 12 percent higher at $255 \mathrm{kPa}$ than that of the conical for the 61 percent FFC cases. In 75 percent FFC cases (fig. 9) the bell nozzle specific impulse is at least 5 percent higher at $500 \mathrm{kPa}, 10$ percent higher at $370 \mathrm{kPa}$, and 14 percent higher at $255 \mathrm{kPa}$. These results are statistically significant and show clearly that the bell nozzle out performed the conical nozzle. The higher performance obtained with lower FFC percentage was expected as discussed above.

Thrust coefficients are plotted for the 61 and 75 percent FFC cases in figures 10 and 11 , respectively, again for each chamber pressure case. As seen in the specific impulse plots, the bell nozzle had the higher performance for both FFC percentages. The thrust coefficients at 61 percent FFC are generally 6 percent higher at $500 \mathrm{kPa}, 7$ percent higher at $370 \mathrm{kPa}$, and 11 percent higher at $255 \mathrm{kPa}$ for the bell nozzle than for the conical. The thrust coefficients at 75 percent $F F C$ are generally 4 percent higher at $500 \mathrm{kPa}, 8$ percent higher at $370 \mathrm{kPa}$, and 11 percent higher at $255 \mathrm{kPa}$ for the bell nozzle than for the conical. Again clearly, the bell nozzle outperforms the conical nozzle for this Reynolds number range of between 20,000 to 40,000 .

\section{Conclusions}

Testing was conducted to directly compare the performance of a bell nozzle designed by the Rao optimization method and a conical nozzle of the same size in the $2 \times 10^{4}$ to $4 \times 10^{4}$ throat Reynolds number range. Previous studies had indicated that an optimized bell nozzle may not outperform a conical nozzle at these Reynolds numbers. To eliminate the effects of injector performance, the same injector and chamber profile were used. Tests were conducted over a mixture ratio range of 4 to 8 for three different chamber pressures and two fuel film cooling levels. Characteristic velocity measurements indicated that the injector and chamber gave the same performance with both nozzles. Plots of vacuum specific impulse and thrust coefficients indicated a higher performance by the bell nozzle. Also, higher performance at the lower FFC percentages for both nozzles. For the throat Reynolds number range of this design, the test results confirm that the Rao optimized bell nozzle yields higher performance than a simple conical nozzle design.

\section{References}

${ }^{1}$ Rao, G.V.R., "Exhaust Nozzle Contour for Optimum Thrust," Jet Propul sion, Vol. 28, No. 6, 1958.

${ }^{2}$ Farley, J.M. and Campbell, C.E., "Performance of Several Method of Characteristics Exhaust Nozzles," NASA TN D293, October 1960.

3“"Liquid Rocket Engine Nozzles," NASA SP-8120, July 1976.

${ }^{4}$ Dunn, C., Kaith, I., O'Shaughnessy, G., Rankel, R., and Rutherford, P., "Design of a High Performance Bell Rocket Nozzle for a High Pressure and Thrust NTR," AIAA 91-3627, September 1991.

${ }^{5}$ Smith, T.A., "Boundary Layer Development as a Function of Chamber Pressure in the NASA Lewis 1030:1 Area Ratio Rocket Nozzle," AIAA-88-3301, 1988.

${ }^{6}$ Grisnik, S.P., Smith, T.A., and Saltz, L.E., "Experimental Study of Low Reynolds Number Nozzles," AIAA Paper 87-0992, May 1987.

${ }^{7}$ Whalen, M.V., "Low Reynolds Number Nozzle Flow Study," NASA TM-100130, July 1987.

${ }^{8}$ Appel, M.A., Schoenman, L., and Berkman, D.K., "Oxygen/Hydrogen Thrusters for the Space Station Auxiliary Propulsion Systems," JANNAF Propulsion Meeting, Vol. 1, 1984, pp. 309-350.

${ }^{9}$ Kushida, R.O., Hermel J., Apfel, S., and Zydowicz, M., "Performance of High Area Ratio Nozzles for a Small Rocket Thrusters," AIAA Paper 86-1573, June 1986.

${ }^{10}$ Morren, S.H., Myers, R.M., Benko, S.E., Arrington, L.A., and Reed B.D., “A Laboratory Model of a Hydrogen/Oxygen Engine for Combustion and Nozzle Studies," NASA TM-106281, AIAA Paper 93-1925, June 1993.

${ }^{11}$ Gordon, S. and McBride, B.J. "Computer Program for Calculation of Complex Chemical Equilibrium Compositions, Rocket Performance, Incident and Reflected Shocks, and Chapman-Jouguet Detonations," NASA Lewis Research Center, NASA SP 273, 1971.

${ }^{12}$ Robinson, P.J., "Space Station Auxiliary Thrust Chamber Technology," Final Report 2210-90-FR, NASA CR-185296, July 1990.

${ }^{13}$ Arrington, L.A. and Schneider, S., "Low Thrust Rocket Test Facility," NASA TM-103206, AIAA Paper 90-2503, July 1990.

14 Rao, G.V.R., "Recent Developments in Rocket Nozzle Configurations," ARS Journal, November 1961, pp. 1488-1494. 
15 Nickerson, G.R., Dang, A.L., Dunn, S S., "The Rao Method Optimum Nozzle Contour Program," George C. Marshall Space Flight Center, NAS8-36863, February 15, 1988.
16“"Handbook for Estimating the Uncertainty in Measurements Made with Liquid Propellant Rocket Engine Systems," Chemical Propulsion Information Agency Document Number 180, April 1969.

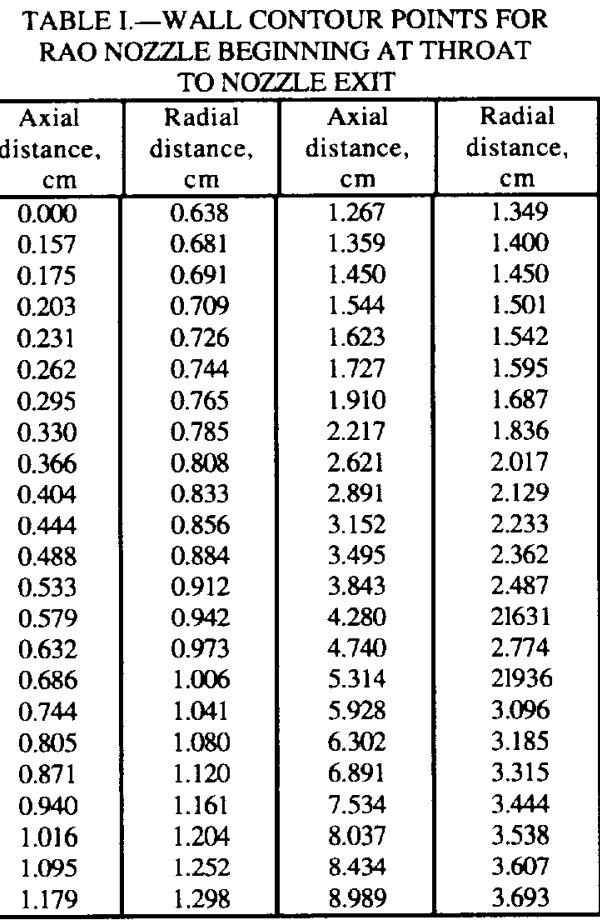

TABLE II.-CROSS SECTIONAL AREAS OF THE BELL AND CONICAL NOZZLES

\begin{tabular}{|l|c|c|}
\hline \multirow{2}{*}{ Location } & \multicolumn{2}{|c|}{$\begin{array}{c}\text { Cross sectional area, } \\
\mathrm{cm}^{2}, \mathrm{~cm}\end{array}$} \\
\cline { 2 - 3 } & $\begin{array}{c}\text { Bell nozzle, } \\
\text { radius }\end{array}$ & $\begin{array}{c}\text { Conical nozzle, } \\
\text { radius }\end{array}$ \\
\hline Chamber & $5.045(1.268)$ & $5.050(1.267)$ \\
\hline Throat & $1.248(0.637)$ & $1.275(0.630)$ \\
\hline Nozzle exit & $42.65(3.687)$ & $42.70(3.685)$ \\
\hline
\end{tabular}

TABLE III.-PERFORMANCE PARAMETER UNCERTAINTY PERCENTAGES FOR THE BELL AND CONICAL NOZZLES AS A FUNCTION

\begin{tabular}{|l|c|c|c|c|c|}
\hline \multicolumn{2}{|c|}{ Uncertainty, \pm percent } & \multicolumn{2}{|c|}{ Bell nozzle } & \multicolumn{2}{c|}{ Conical nozzle } \\
\cline { 3 - 6 } \multicolumn{2}{|c|}{} & $61 \%$ FFC & $75 \%$ FFC & $61 \%$ FFC & $75 \%$ FFC \\
\hline $\begin{array}{l}\text { Specific } \\
\text { impulse }\end{array}$ & $500 \mathrm{kPa}$ & $\begin{array}{c}2.6 \\
(4.0)\end{array}$ & 2.6 & 1.1 & 1.1 \\
& $370 \mathrm{kPa}$ & $\begin{array}{c}3.3 \\
(6.8)\end{array}$ & 2.9 & 1.4 & 1.5 \\
& $255 \mathrm{kPa}$ & 5.7 & 4.6 & 2.0 & 1.9 \\
\hline $\begin{array}{l}\text { Characteristic } \\
\text { velocity }\end{array}$ & $500 \mathrm{kPa}$ & 1.2 & 1.1 & 1.2 & 1.1 \\
& $370 \mathrm{kPa}$ & 1.6 & 1.4 & 1.5 & 1.5 \\
& $255 \mathrm{kPa}$ & 2.4 & 2.1 & 2.0 & 2.0 \\
\hline $\begin{array}{l}\text { Thrust } \\
\text { coefficient }\end{array}$ & $500 \mathrm{kPa}$ & $\begin{array}{c}2.6 \\
(4.1)\end{array}$ & 2.6 & 0.4 & 0.5 \\
& $370 \mathrm{kPa}$ & $\begin{array}{c}3.3 \\
(7.0)\end{array}$ & 2.9 & 0.7 & 0.7 \\
& $255 \mathrm{kPa}$ & 6.0 & 4.5 & 1.1 & 0.9 \\
\hline
\end{tabular}




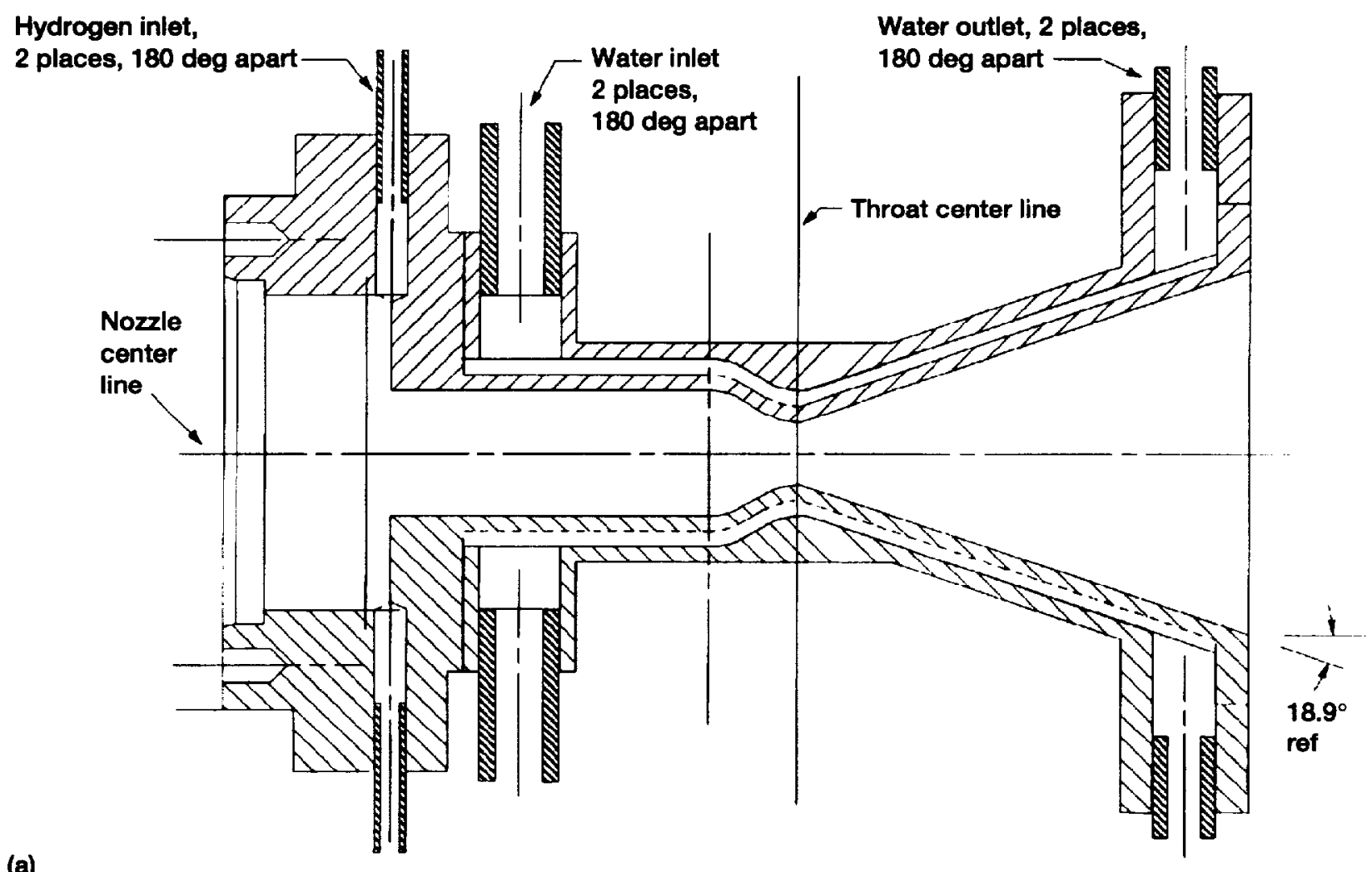

(a)

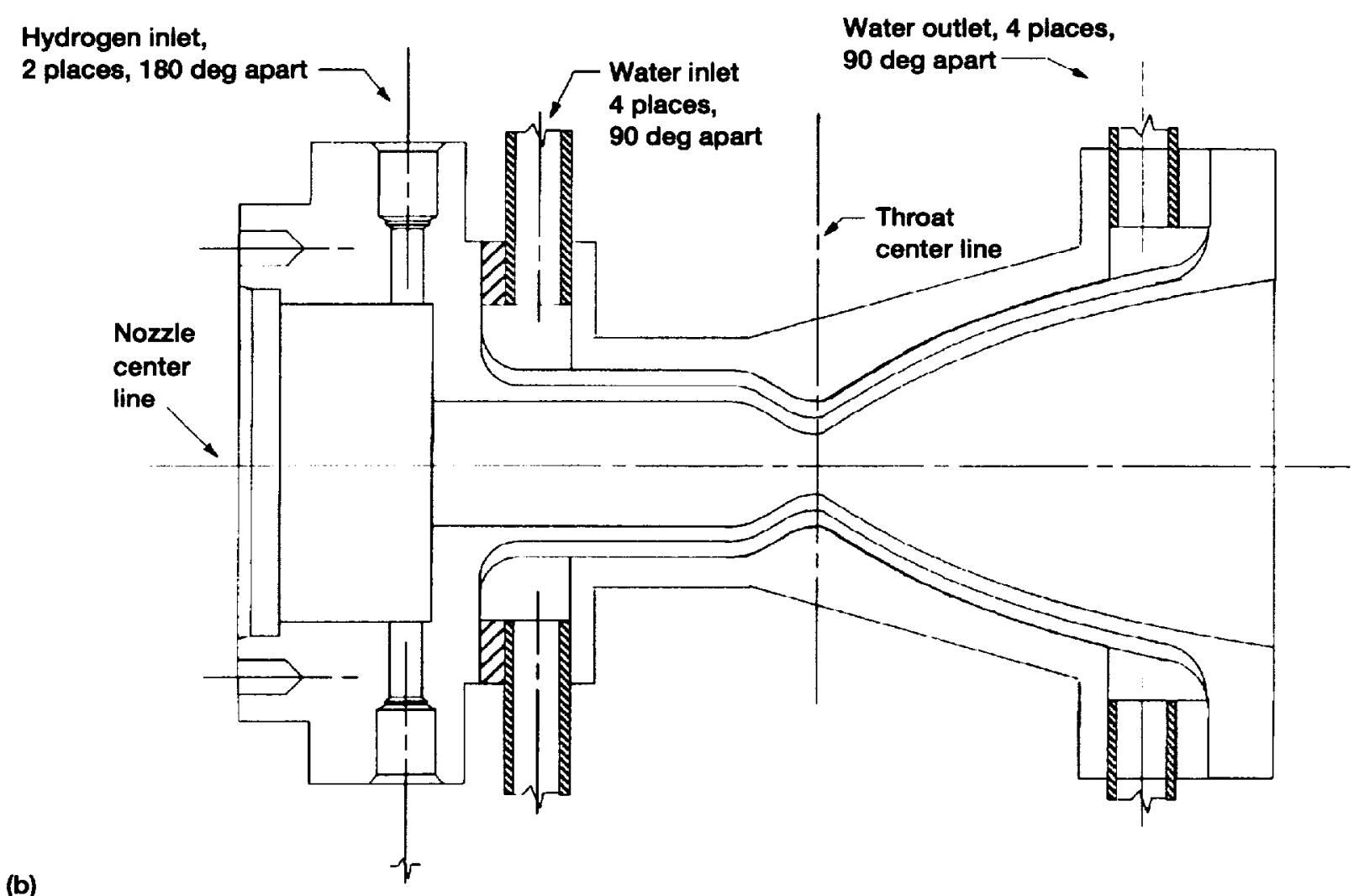

Figure 1.- (a) Schematic of conical nozzle. (b) Schematic of bell contoured nozzle. 


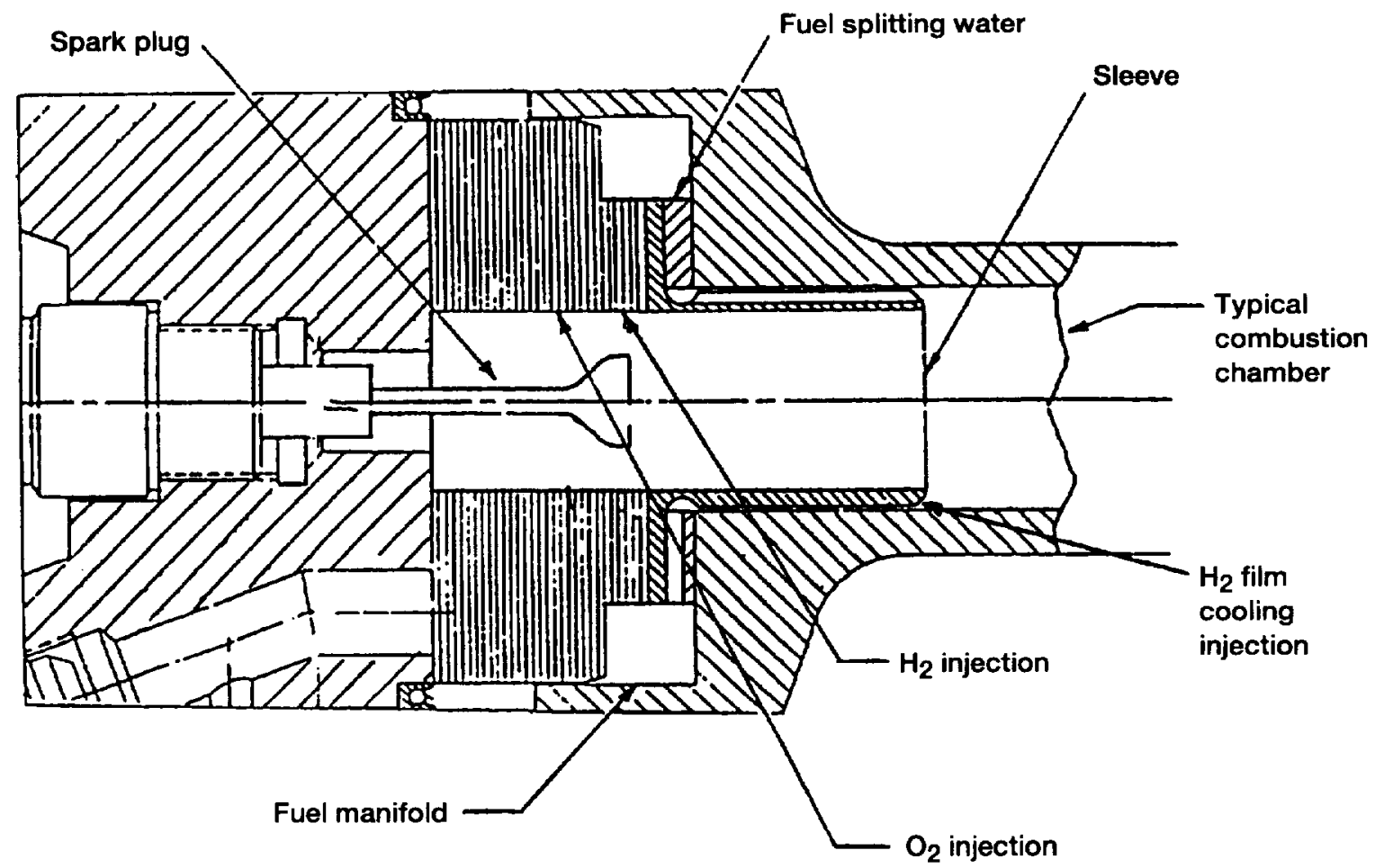

Figure 2.-Details for Aerojet SN 03 injector.

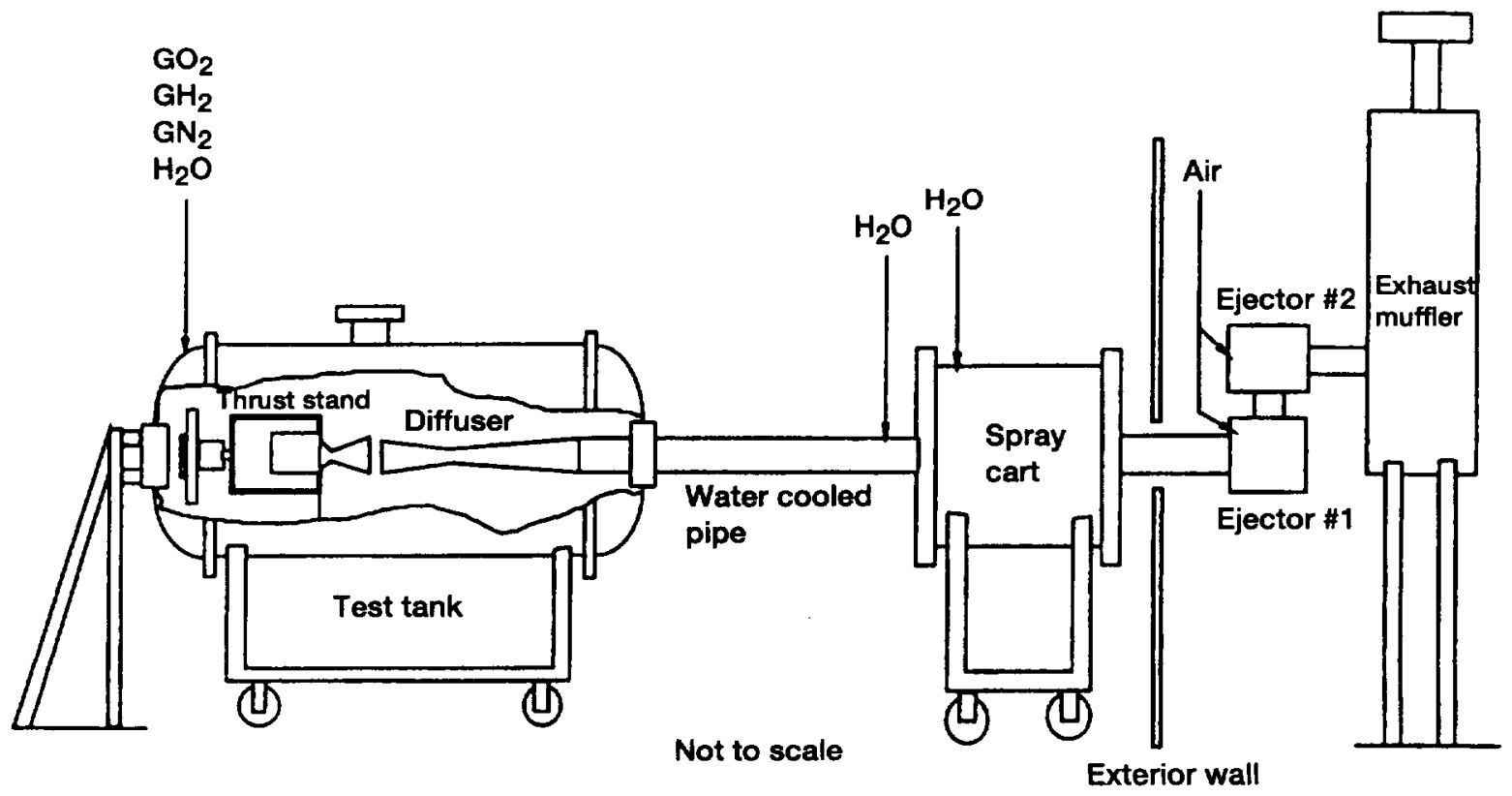

Figure 3.-Schematic of test rig. 


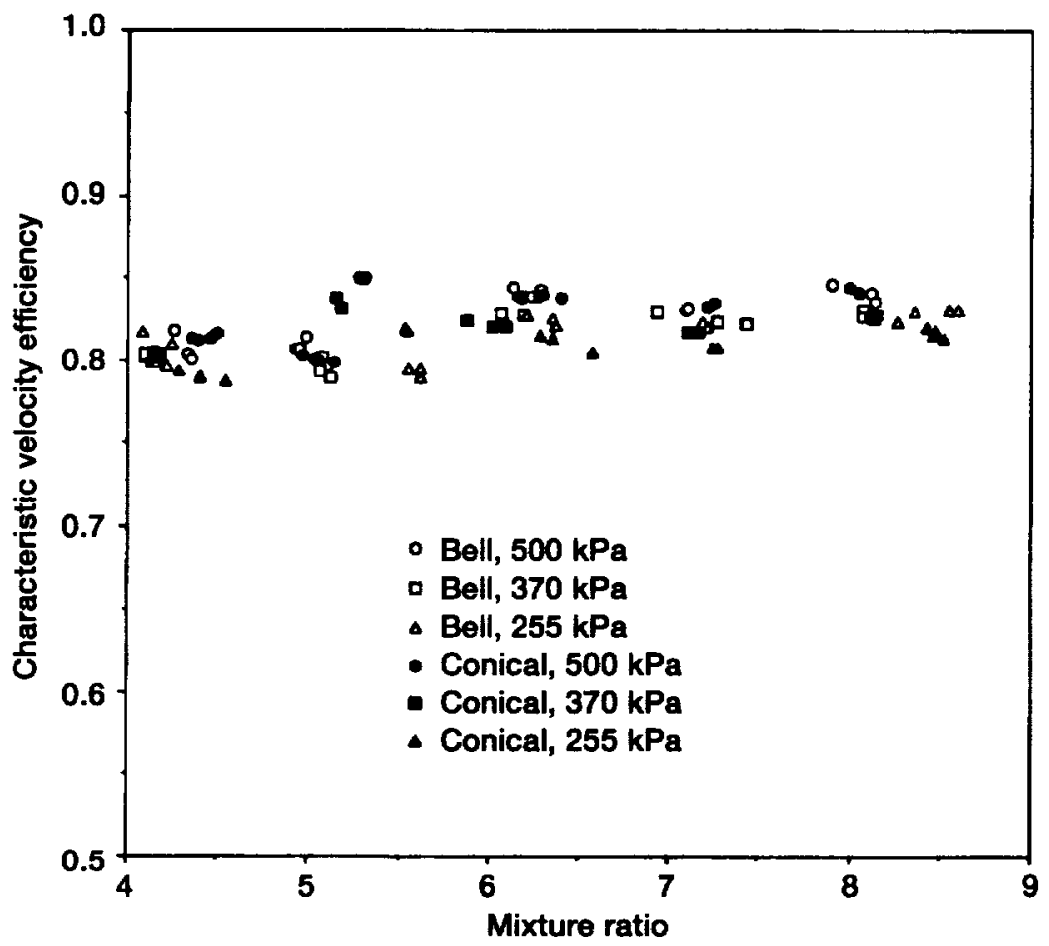

Figure 4.-Characteristic velocity efficiency versus mixture ratio for 61 percent FFC for both bell and conical nozzles.

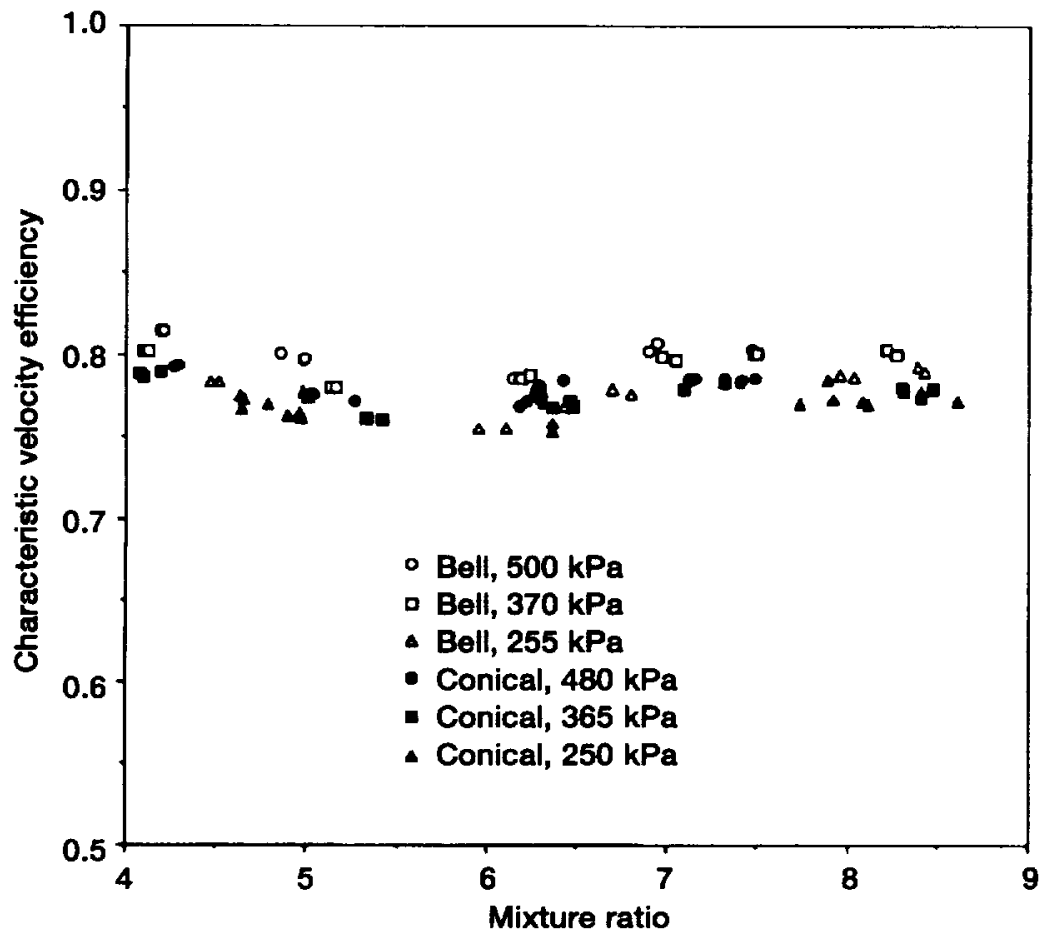

Figure 5.-Characteristic velocity efficiency versus mixture ratio for 75 percent FFC for both bell and conical nozzles. 


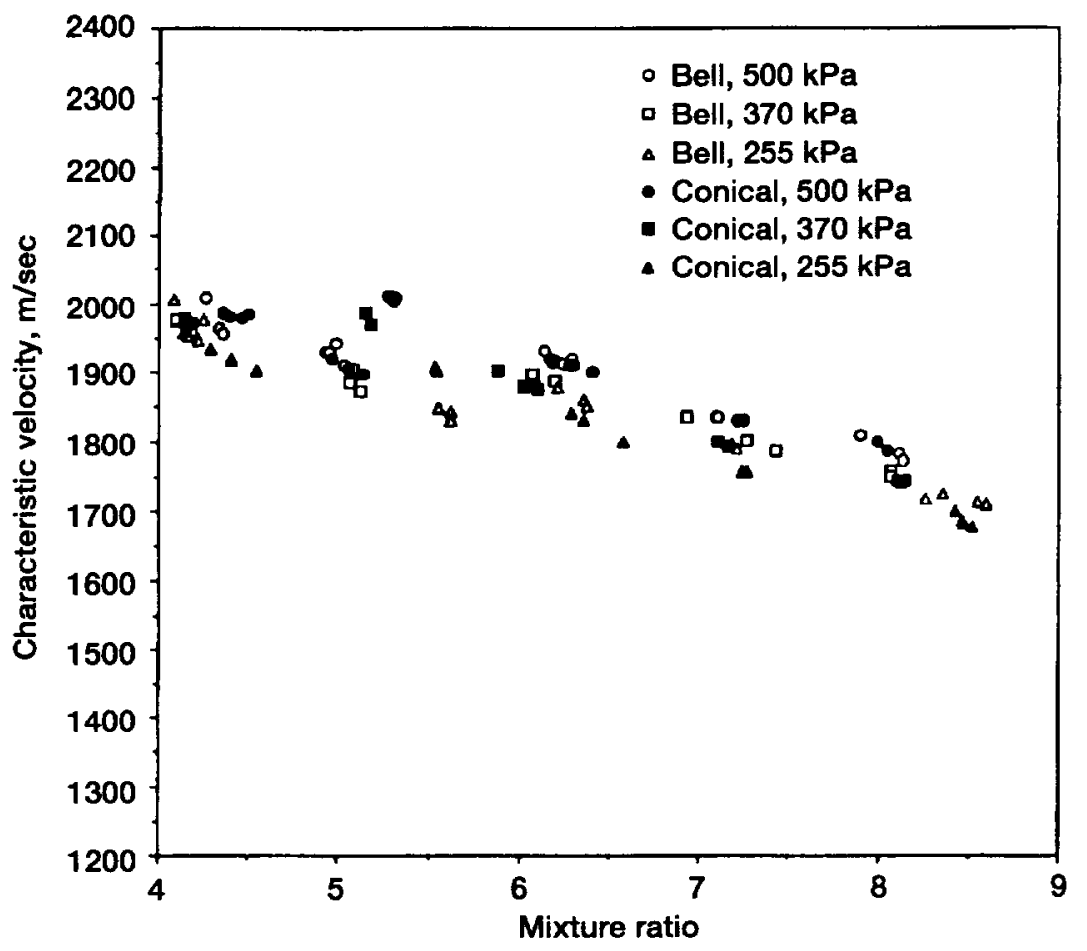

Figure 6.-Characteristic velocity versus mixture ratio for 61 percent FFC for both bell and conical nozzles.

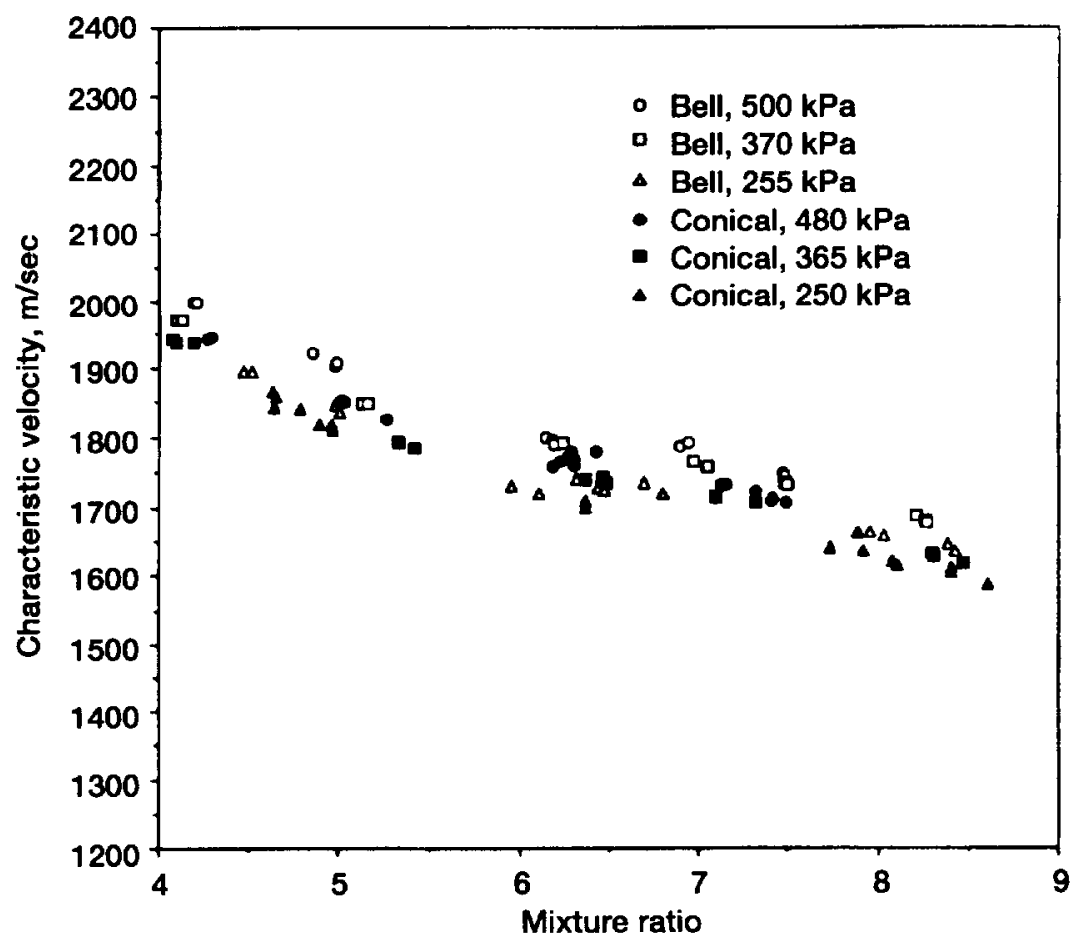

Figure 7.-Characteristic velocity versus mixture ratio for 75 percent FFC for both bell and conical nozzles. 


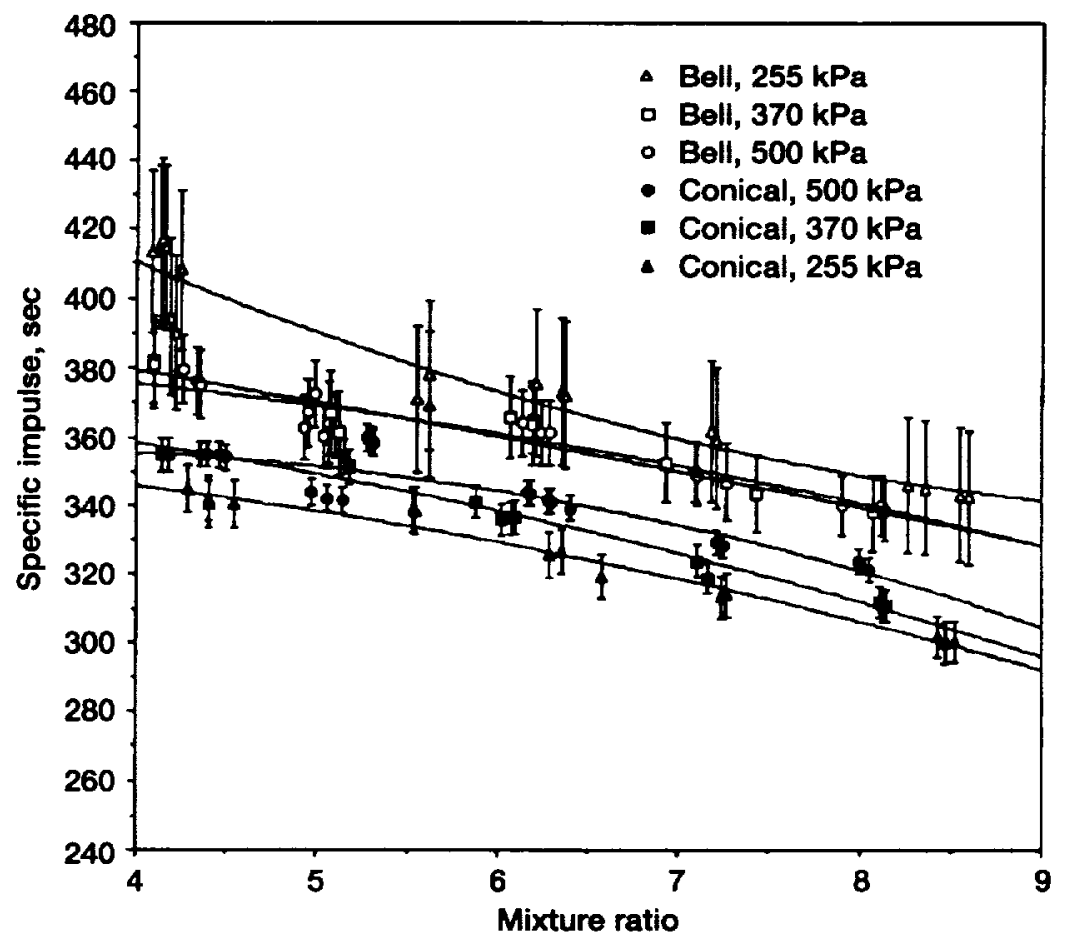

Figure 8.-Specific impulse versus mixture ratio for 61 percent FFC for both bell and conical nozzles, with uncertainty bars.

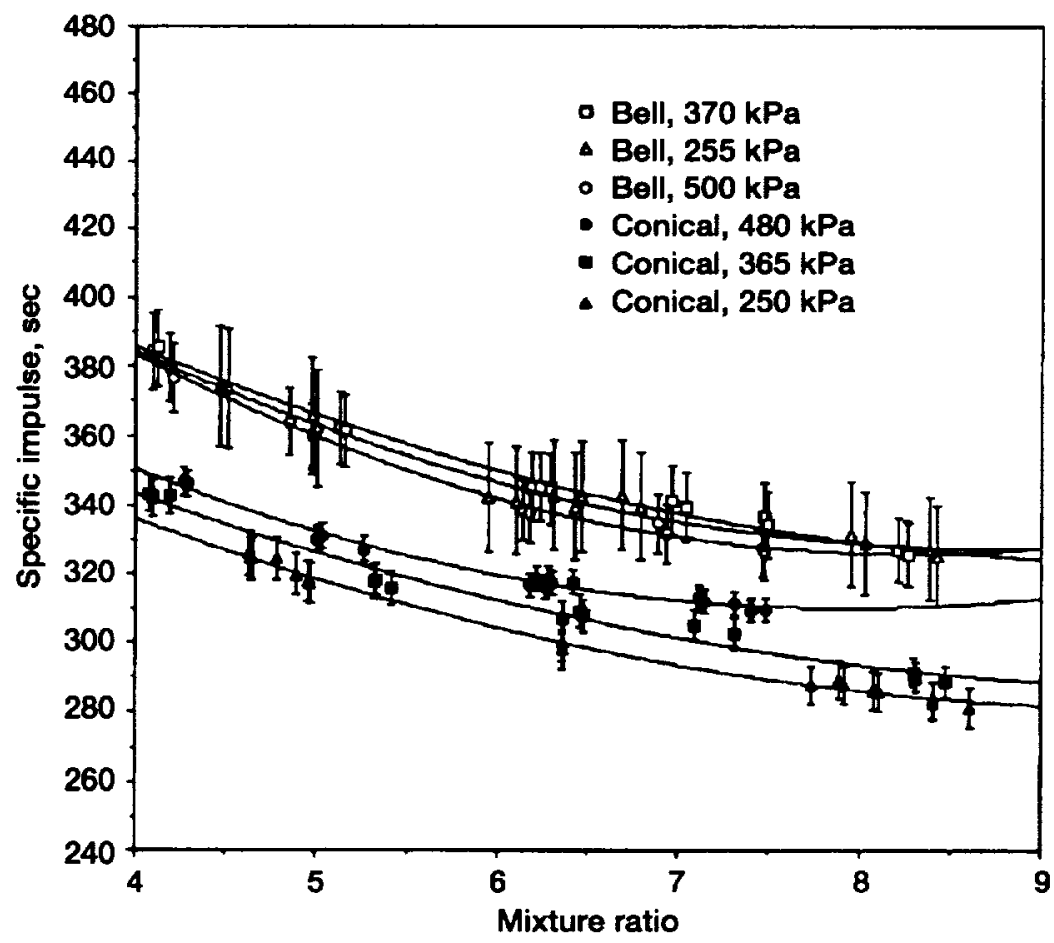

Figure 9.-Specific impulse versus mixture ratio for 75 percent FFC for both bell and conical nozzles, with uncertainty bars. 


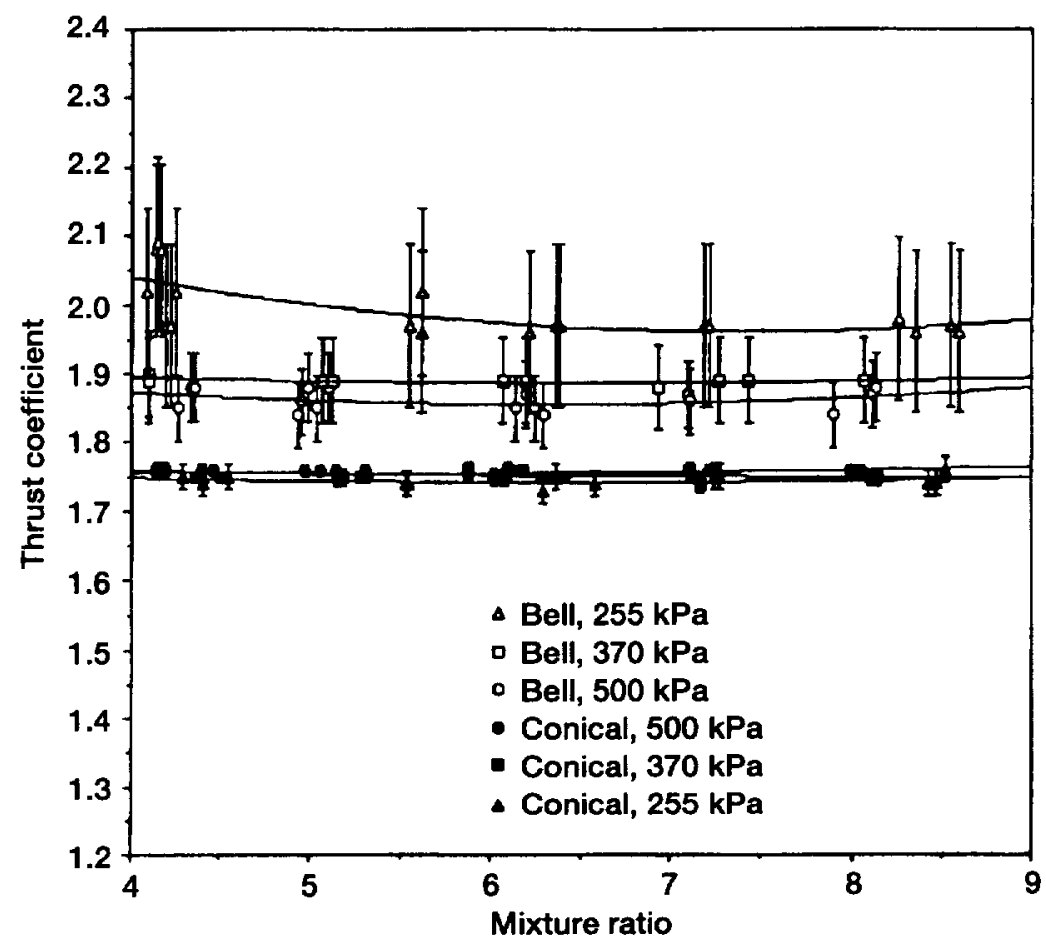

Figure 10.-Thrust coefficient versus mixture ratio for 61 percent FFC for both bell and conical nozzles, with uncertainty bars.

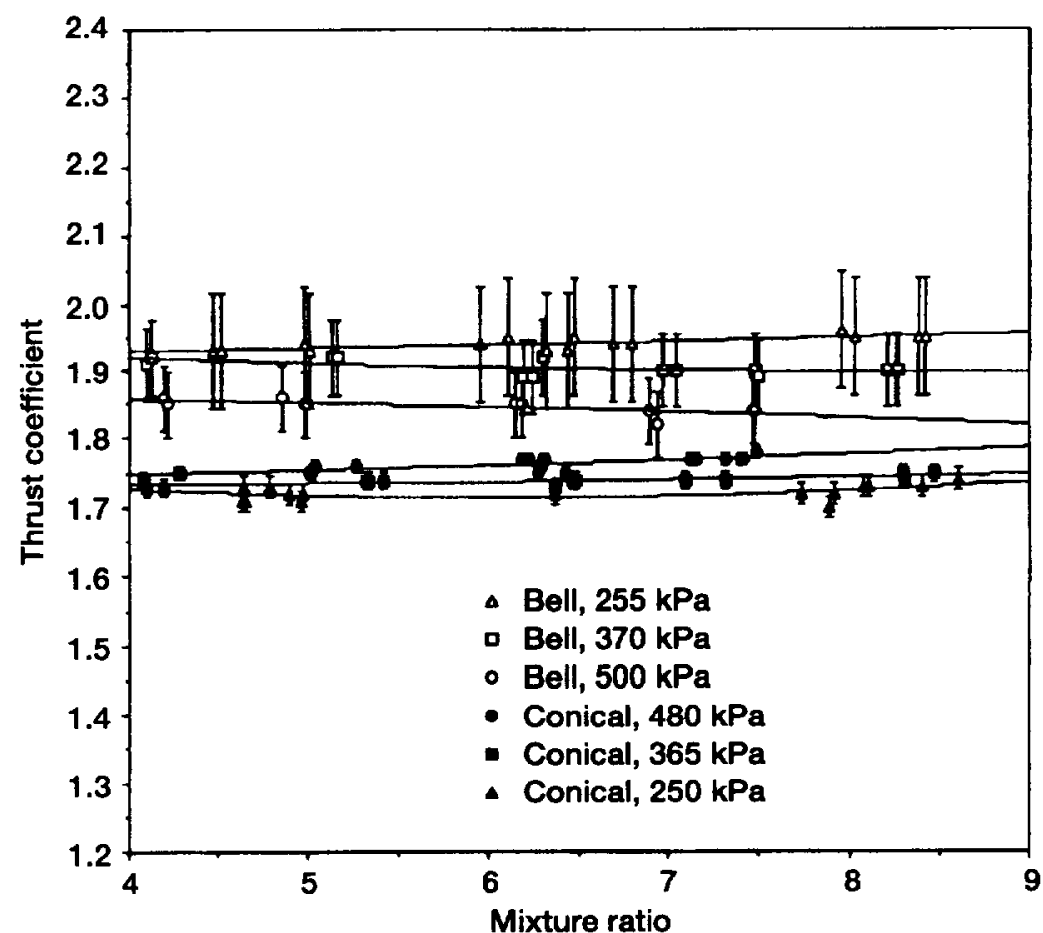

Figure 11.-Thrust coefficient versus mixture ratio for 75 percent FFC for both bell and conical nozzles, with uncertainty bars. 
Public reporting burden for this collection of information is estimated to average 1 hour per response, including the time for reviewing instructions, seanching existing data sources, gathering and maintaining the data needed, and completing and reviewing the collection of information. Send comments regarding this burden estimate of any other aspect of thi Davis Highway, Suite 1204, Arlington, VA 22202-4302, and to the Office of Management and Budget, Paperwork Reduction Project (0704-0188), Washington, DC 20503.

\begin{tabular}{|l|c|r|}
\hline 1. AGENCY USE ONLY (Leave blank) & $\begin{array}{r}\text { 2. REPORT DATE } \\
\text { August } 1996\end{array}$ & $\begin{array}{r}\text { 3. REPORT TYPE AND DATES COVERED } \\
\text { Technical Memorandum }\end{array}$ \\
\hline
\end{tabular}

4. TITLE AND SUBTITLE

5. FUNDING NUMBERS

A Performance Comparison of Two Small Rocket Nozzles

6. AUTHOR(S)

WU $-242-70-02$

Lynn A. Arrington, Brian D. Reed, and Angel Rivera, Jr.

\section{PERFORMING ORGANIZATION NAME(S) AND ADDRESS(ES)}

National Aeronautics and Space Administration

Lewis Research Center

Cleveland, Ohio 44135-3191
8. PERForming ORGANIZATION REPORT NUMBER

E-10360
9. SPONSOAINGMONTORING AGENCY NAME(S) AND ADDRESS(ES)

National Aeronautics and Space Administration

Washington, D.C. 20546-0001
10. SPONSORINGMONTORING AGENCY REPORT NUMBER

NASA TM-107285

AIAA-96-2582

11. SUPPLEMENTARY NOTES

Prepared for the 32nd Joint Propulsion Conference cosponsored by AIAA, ASME, SAE, and ASEE, Lake Buena Vista, Florida, July 1-3, 1996. Lynn A. Arrington, NYMA, Inc., 2001 Aerospace Parkway, Brook Park, Ohio 44142 (work performed under NAS3-27186); Brian D. Reed, NASA Lewis Research Center; Angel Rivera, Jr., Undergraduate Senior, University of Texas, San Antonio, Texas. Responsible person, Brian D. Reed, organization code 5330, (216) 977-7489.

12a. DISTRIBUTION/AVAILABILITY STATEMENT 12b. DISTRIBUTION CODE

Unclassified - Unlimited

Subject Category 18

This publication is available from the NASA Center for AeroSpace Information, (301) 621-0390.

13. ABSTRACT (Maximum 200 words)

An experimental study was conducted on two small rockets (110N thrust class) to directly compare a standard conical nozzle with a bell nozzle optimized for maximum thrust using the Rao method. In large rockets, with throat Reynolds numbers of greater than $1 \times 10^{5}$, bell nozzles outperform conical nozzles. In rockets with throat Reynolds numbers below $1 \times 10^{5}$, however, test results have been ambiguous. An experimental program was conducted to test two small nozzles at two different fuel film cooling percentages and three different chamber pressures. Test results showed that for the throat Reynolds number range from $2 \times 10^{4}$ to $4 \times 10^{4}$, the bell nozzle outperformed the conical nozzle. Thrust coefficients for the bell nozzle were approximately $4-12 \%$ higher than those obtained with the conical nozzle. As expected, testing showed that lowering the fuel film cooling increased performance for both nozzle types.

\begin{tabular}{|c|c|c|}
\hline \multicolumn{3}{|c|}{$\begin{array}{l}\text { 14. SUBJECT TERMS } \\
\text { Nozzle; Rao; Conical; Low thrust; Reynolds number }\end{array}$} \\
\hline $\begin{array}{l}\text { 17. SECURITY CLASSIFICATION } \\
\text { OF REPORT } \\
\text { Unclassified }\end{array}$ & $\begin{array}{l}\text { 18. SECURITY CLASSIFICATION } \\
\text { OF THIS PAGE } \\
\text { Unclassified }\end{array}$ & $\begin{array}{l}\text { 19. SECURITY CLASSIFICATION } \\
\text { OF ABSTAACT } \\
\text { Unclassified }\end{array}$ \\
\hline
\end{tabular}

NSN 7540-01-280-5500 


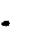




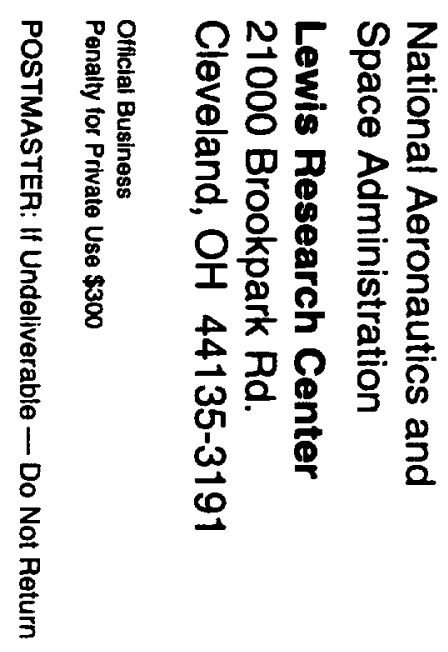

